\title{
UNESCO active learning approach in optics and photonics leads to significant change in Morocco
}

K. Berrada, R. Channa, A. Outzourhit, M. Azizan, A. Oueriagli

K. Berrada, R. Channa, A. Outzourhit, M. Azizan, A. Oueriagli, "UNESCO active learning approach in optics and photonics leads to significant change in Morocco," Proc. SPIE 9289, 12th Education and Training in Optics and Photonics Conference, 92890W (17 July 2014); doi: 10.1117/12.2070289

SPIE Event: 12th Education and Training in Optics and Photonics Conference, 2013, Porto, Portugal 


\title{
UNESCO Active Learning approach in Optics and Photonics leads to significant change in Morocco
}

\author{
K. Berrada, R. Channa, A. Outzourhit, M. Azizan, A. Oueriagli \\ Cadi Ayyad University - Faculty of Sciences Semlalia \\ ESIAM - Department of Physics \\ BP: 2390 - Marrakech Morocco \\ Corresponding author: berrada@uca.ma
}

\begin{abstract}
There are many difficulties in teaching science and technology in developing countries. Several different teaching strategies have to be applied in these cases. More specifically, for developing countries competencies in teaching science in the introductory classroom has attracted much attention. As a specific example we will consider the Moroccan system. In most developing countries everything is moving so slowly that the progress stays static for development. Also, any change needs time, effort and engagement. In our case we discovered that many teachers feel uncomfortable when introducing new teaching methods and evaluation in classes at introductory physics. However, the introduction of an Active Learning in our curricula showed difficulties that students have in understanding physics and especially concepts. Students were interested in having Active Learning courses much more than passive and traditional ones. Changing believes on physical phenomena and reality of the world students become more attractive and their way of thinking Science changed. The main philosophy of fostering modern hands-on learning techniques -adapted to local needs and availability of teaching resources- is elaborated. The Active Learning program provides the teachers with a conceptual evaluation instrument, drawn from relevant physics education research, giving teachers an important tool to measure student learning. We will try to describe the UNESCO Chair project in physics created in 2010 at Cadi Ayyad University since our first experience with UNESCO ALOP program. Many efforts have been done so far and the project helps now to develop more national and international collaborations between universities and Regional Academies of Education and Training. As a new result of these actions and according to our local needs, the translation of the ALOP program into Arabic is now available under the auspice of UNESCO and encouragement of international partners SPIE, ICTP, ICO and OSA.
\end{abstract}

\section{Introduction}

Teaching physics at Moroccan universities can no longer simply use traditional methods at large classrooms. Physics is a discipline full of concepts and issues that need a lot of demonstrations and it is rare to find instructors with real demonstrations to overcome these problems. This is not because physics teachers do not believe in the value of observations, but the fact that there is a huge lack of physics demonstrations in most universities. Another difficulty in teaching physics arises from the enduring need to prepare young professors, teaching assistants as well as pre-college teachers to teach physics effectively and to use demonstrations in their classrooms. Research on pedagogy and teaching physics can guide the design of special training courses that meet the needs of young professors, teaching assistants, and pre-college teachers [1]. The objectives and instructional methods that should characterize such training courses will be described as Active Learning approach in this work. 


\section{I.1. An historical overview}

UNESCO Chair on Hands-on physics education (Enseignement de la physique par la pratique) created in Morocco [2] is a project inspired from UNESCO Active Learning programs, especially the successful one developed in Optics and Photonics (ALOP) which was awarded the SPIE best educational project in San Diego in 2010 [3]. Based on educational goals UNESCO designed curriculum on optics and photonics because it is an emerging field in physics and more adaptable to research and educational conditions in many developing countries. Also because the program is basically applied geometrical and physical optics -topics where teachers often suffer from the lack of equipment, especially in developing countries.

Morocco has been one of countries where ALOP was disseminated at large scale for both national and higher education for more than 5 years now. According to its objectives to improve best teaching practices in optics and photonics in classroom, UNESCO Chair project is became in 2010 a national project aiming at spreading a new culture of learning first in optics (2005-2010) before generalizing it to other fields such as Mechanics and Electricity (2010-2012). More than that, this initiative is planning the same actions in Biology and Chemistry. ALOP project is developing activities based on teacher training curriculum on the themes [4]:

- Introduction to Light and Geometrical Optics

- Optics of the Eye

- Interference - Diffraction and Spectroscopy

- Environmental Optics

- Optics in communication

Since our first participation to the $2^{\text {nd }}$ UNESCO ALOP workshop in Tunisia in March 2005, a team from Cadi Ayyad University was created and hosted in April 2006 the $3^{\text {rd }}$ ALOP UNESCO workshop in Marrakech with the help of many partners: ICTP, EPS-IGPD, NSF, SPIE,... Following our engagement to the project, the same year, we have been invited to join coming activities, first as an international observer during the $4^{\text {th }}$ Asian ALOP UNESCO workshop at Miranda House University of Delhi in India [5] on December 2006 and then as facilitator for next editions. In addition to that and in collaboration with colleagues from the University of Tunis we decided to start working on the ALOP UNESCO French program which was published under the auspice of UNESCO later. Two successful editions were organized in Morocco and then in Tunisia in November 2006. Those initiatives attracted the attention of the Regional Academy of Education and Training of Rabat (AREF). The collaboration with AREF started on 2007 with a partnership between Cadi Ayyad University, UNESCO and AREF. A team of 12 inspectors from AREF Rabat were involved in the Active Learning project and many sessions were organized to train others inspectors and then teachers. AREF, UNESCO, ICTP and SPIE have supported all these activities. While the ALOP program continues to be developed in Morocco, activities were conducted in several places in the world. To date, there have been sixteen ALOPs: Dhulikhel, Nepal, 17-21 December, 2011, Kigali, Rwanda, 14-18 November, 2011, Quezon City, The Philippines, 1419 November, 2010, Constantine, Algeria, 14-19 May, 2010, Santiago, Chile, 11-15 January, 2010, Dhulikhel, Nepal, 11 - 16 July, 2009, Bogota, Colombia, 23-27 June, 2009, Douala, Cameroon, 2-6 Dec., 2008, Lusaka, Zambia, 22-26 September, 2008, San Luis Potosi, Mexico, 5-11 December, 2007, Sao Paula, Brazil, 22-27 July, 2007, Dar es Salaam, Tanzania, 
5-11 July, 2007, New Delhi, India, 6-11 November, 2006, Marrakech, Morocco, 23-28 April, 2006, Monastir, Tunisia, 22 March-2 April, 2005, and Cape Coast, Ghana 2004. The work on the French edition was finalized and published by UNESCO in 2010 [6]. In 2012, the team of AREF has also prepared a contribution to this program and the Arabic version of ALOP was published. Between the years 2009-2010, more than 1000 High school teachers benefited from ALOP program in their classes and were trained by AREF ALOP team themselves.

\section{I.2. Active Learning in Optics and Photonics basis approach}

Active learning in physics, developed over the last decade, has been tested in many developed countries to improve the understanding of the basic physics concepts. In this teaching strategy, students are encouraged to build their knowledge of physics concepts by direct and real observations of the physical world and using a learning cycle, including: individual and collective predictions, discussions in small groups, observations of experiment and comparison with previous predictions. This learning cycle can be represented by the following PODS steps:

\section{- Prediction \\ - Observation \\ - Discussion \\ - Synthesis}

In this way, and because of the strong engagement, students become aware of the differences between their beliefs and the laws of physics that govern the physical world. The active learning method, evolutionary result of several years of research in science education in physics, has led to a significant improvement in understanding concepts [7-9]. It reproduces the scientific process in the classroom and helps the development of good reasoning skills in physics. Guided by results from research practices and action research, this approach gives priority to offering learners the opportunity to control fundamental concepts through experimentation.

The change in the role of the teacher is of an extreme importance when active learning techniques are introduced in class. Both in developed and developing countries, it may be difficult for a physics teacher to set aside its traditional role as the authority explaining everything to that of a guide, using the active learning techniques. To make this transition, it is necessary to accept the evidence that beginners often do not learn effectively, even the most logical explanations given by their teachers, and believe in the effectiveness of active learning tools in teaching concepts. The ease of this transition depends not only on the willingness to abandon the role of authority, but also a number of cultural factors that differ from one country to another. This is the ultimate challenge in presenting workshops on active learning in different parts of the developing world, and also a major reason for recruiting and training local trainers that have been incorporated into this project.

Active Learning in Optics and Photonics demonstrated in the US and other developed countries [10] its capacity to enhance student's understanding of basic physics concepts. In this learning strategy students are guided to construct their knowledge of physics concepts by direct observations of the physical world with Hands on -activity based on activities in groups following PODS steps.

\section{State of the art of UNESCO Chair initiative in Morocco}

UNESCO Chair project was created at Cadi Ayyad University according to all efforts and 
initiatives developed during the period 2005-2010 and with support and help of many national and international partners who have contributed to our activities in Morocco last five years activities. Its objectives can be described as follow:

- Promoting teaching physics by encouraging the use of active methods

- Providing teachers with tools for motivating student learning

- Contributing to the development of new curricula in physics

- Raising awareness of the role of conceptual evaluation in the classroom

- Using appropriate and low-cost pedagogical techniques and apparatus

- Emphasizing learning based on educational technologies in Lab activities

The project takes also benefit from two important initiatives started during the same period (1) the Moroccan Emergency program of Ministry of National Education between 2009-2012, which focused some of its actions on improving teaching sciences and technology through out:

- Inquiry-based learning sciences,

- French program called la main à la pate

- Computer-based learning techniques, to reinforce teaching sciences.

(2) the UNESCO biennium 2010-2011 of Natural Sciences Sector where goals were focused on:

- Improving the quality of teaching science and mathematics,

- Development of a strategic framework for teaching science and mathematics in a country,

- Training teachers on innovative approaches to best teaching science.

For all of that, UNESCO Chair project has been considered as a model for training teachers and tried to answer to the needs for both national and regional education.

We have also thought that the best way to disseminate this new approach in teaching sciences will be possible through Regional Academies in Morocco. The first proposal was made early in 2008 to AREF of Rabat and its region. Optics and photonics were the first actions we started in Morocco. The program was designed in collaboration with inspectors and professors of physics and many training sessions have been organized so far from the north to the south in Morocco. Both equipment and curricula were adapted and designed for our national educational system. During the years 2010 and 2011, Active Learning approach was extended to Mechanics and Electricity. So far all inspectors of sixteen AREFs were trained and are now able to train themselves other teachers of high school physics. The work is lead by the National Centre for Innovation and Experimentation (CNIPE) of the Ministry of National Education of Morocco.

\section{Results of disseminating actions}

In this part we will describe the results obtained from the successful actions of the UNESCO project of Cadi Ayyad University between the years 2005 to 2012. Actions have concerned collaborative workshops at national and international level, production of training manuals, teacher training sessions, conferences, seminars, and national and international projects.

In collaboration with ALOP international team, Moroccan team has participated; organized or/and facilitated workshops in Morocco (2006-2012), Tunisia (2005-2012), India (2006), 
Zambia (2008), Cameron (2008), Algeria (2010) and Philippines (2010). Locally, ALOP workshops have been a very large success and attracted more participants. Moroccan team conducted many activities in optics and photonics in different universities and AREFs as follow:

- Faculty of Sciences Semlalia in 2006 (International edition)

- Faculty of Sciences Semlalia in 2006 (French edition)

- AREF Rabat 2007 (French edition)

- AREF Marrakech 2008 (French edition)

- AREF Rabat 2008 (French edition)

- National School of Applied Sciences in Marrakech (French edition)

- National School of Applied Sciences in Tangier 2009 (French edition)

- CNIPE in Rabat 2010 (French edition)

- Faculty of Sciences and Techniques in Beni Mellal 2009 (French edition)

- Normal High School in Martil Tetouan 2009 (French edition)

- Faculty of Sciences Semlalia in Marrakech 2010 (French edition)

- National School of Applied Sciences in Safi (French edition)

- CNIPE Training session for 8 AREFs of the South of Morocco in Marrakech 2010

- CNIPE Training session for 8 AREFs of the North of Morocco in Tangier 2010

For these workshops a very large number of sets of equipments in Optics and Photonics were fabricated and delivered locally to the host. As example around 150 full sets of 10 Kits for each module were designed and distributed for free to participants. Thanks to UNESCO, ICTP, SPIE and Ministry of National Education of Morocco for their great support to success the project.

In order to facilitate the use of the program in other languages, we have translated into French the ALOP training manual in collaboration with a team from University of Tunis leaded by Prof. Souad Lahmar and the manual was published in 2008. According to the need of high schools, the AREF Rabat translated the manual into Arabic and UNESCO published it in 2012. Latino American group also translated ALOP program into Spanish in 2011. ALOP activities inspired the team at Cadi Ayyad University and Mechanics and Electricity are now following the same way (workshops, training sessions, manuals,..). At Cadi Ayyad University, all parts of elementary physics were prepared with more conceptual approach and active learning process. We are now working on how to introduce conceptual approach in teaching physics in our curricula from next September.

ALOP was also a collaborative project since it brought much cooperation with many professional groups in the field of physics education. We had a great collaboration with Prof. Zohra Ben Lakhdar from Tunisia since 2005. Also, Prof. David Sokoloff (Oregon University) and Priscilla Laws (Dinkinson College) have visited us many times and many activities were done with their help and support since 2006. Prof. Alex Mazzolini from Swinburne University visited us in 2006 and spent around a month working together to set up program on Optical communication for National School of Applied Sciences Marrakech in 2008 and then in 2010 for an ALOP at National School of Applied Sciences Safi. Prof. Ivan Culaba from Ateneo Manila University collaborated with us on Atmospheric optics since 2006, and also on Active learning in Mechanics in 2010. Prof. Souad Lahmar from Tunis University collaborated with us in translating ALOP manuals but also as facilitated modules for AREF during the period 
2006 and 2009. Prof. Imrana Ashraf from Islamabad University spent one month working with our group on Spectroscopy and was supported by ICO in 2010. In November 2010, the International Union of Pure and Applied Physics approved the host of its International Conference on Physics Education at Cadi Ayyad University, which was held under the High Patronage of His Majesty the King Mohammed VI. Around 450 participants attended this conference in Marrakech representative 39 countries.

We will not forget to mention that all those initiatives put many colleagues from AREFs and universities from Morocco and from the region all together networking on the area of optics and photonics and activities have been also extended also to scientific research.

\section{Conclusion}

UNESCO Active learning experience in Optics and Photonics has been enlarged in a number of different educational settings. Many Moroccan universities and AREFs took part in training sessions between the years 2006 to 2012. The original ALOP manual has been translated and published into French and then Arabic and now are used by professors in some High schools. Since 2005, evaluation tools were tested and applied to both students and teachers and shown the real benefit of the active learning method based on inquiry learning approach. The project was very helpful to disseminate officially those initiatives in many places in Morocco and to improve other fields of physics such Mechanics and Electricity.

The cooperation with ICTP Italy, Optical Society of America, International Committee for Optics, and SPIE International Society for Engineering Optics were for a great help to us to foster and to improve teaching Optics and Photonics at a large scale in Morocco. Topics are now subject of discussion to launch professional License and Specialized Master in our University for coming years. However, the success of this project requires also development of scientific research and through educational research that need to be approved in Morocco. We would like to conclude that ALOP program and Unesco Chair projects are just models to follow. Results show us that it is necessary to enhance physics education throughout developing countries. Those initiatives remind us that international collaboration is also an essential element to improve physics education.

We hope that through this project new programs incorporating physical activity methods and experimentation can be offered at national, regional and African level, where education reforms have already been implemented.

\section{Acknowledgments}

We could not have developed these actions through UNESCO Chair without the help of the International ALOP team on the name of Minella Alarcon (Philippines), David Sokoloff (USA), Zohra Ben Lakhdar (Tunisia), Alex Mazzolini (Australia), Ivan Culaba (Philippines), Joel Maquiling (Philippines), Vengu Lakshminarayanan (Canada), and Joe Niemela (ICTP Italy). Many thanks to the group for their collaboration on this inspiring adventure in active learning in optics and photonics. We highly appreciate the hard work of all inspectors and professors of physics at AREF Rabat on the name of the Director, Prof. Tijania Fertat. Our thanks also went to Prof. Moulay Youssef Elazhari and Mohamed Hosni from CNIPE at Moroccan Ministry of National Education who believed since the beginning to the introduction of the Active Learning approach as an innovative Inquiry-learning sciences solution for high schools according to the objectives of the Emergency program of Morocco. We are also very grateful to our colleagues from Department of physics of Faculty of 
Sciences Semlalia for assisting us during the period 2005-2012, and to the students of Semester II Physics section for their participation actively in the assessments as well as in the testing of laboratory activities. This work was supported in Morocco by Cadi Ayyad University, Unesco, ICTP Abdus Salam, SPIE, ICO and Ministry of National Education, we are very grateful to them for their endorsement and financial support brought to the project.

\section{References}

[1] L.C. McDermott, P.S. Shaffer. and C.P. Constantinou, "Preparing teachers to teach physics and physical science by inquiry," Physics Education 35 (6) 411 (2000).

[2] http://www.unesco.org/fr/university-twinning-and-networking/access-by-region/arabstates/morocco/unesco-chair-in-physics-904/.

[3] http://spie.org/x42219.xml.

[4] David R. Sokoloff, "Active learning of introductory optics: Strategies for the U.S. and the developing World“, Lat. Am. J. Phys. Educ. Vol. 6, Suppl. I (2012).

[5] http://www.mirandahouse.ac.in/alopasia2006/.

[6] ALOP Manuel Training English version, (C) UNESCO 2006, Traduction en Français 2010.

[7] R. K. Thornton, and D. R. Sokoloff, "Learning motion concepts using real-time, microcomputer-based laboratory tools," Am. J. Phys. 58, 858-867 (1990).

[8] L.C. McDermott, "Millikan lecture 1990: What we teach and what is learned -closing the gap", Am. J. Phys 59, 301-315 (1991).

[9] D. Hestenes, M. Wells and G. Schwackhammer, "Force Concept Inventory," The Physics Teacher 30:3, 141-158 (1992).

[10] David R Sokoloff, Priscilla W Laws and Ronald K Thornton, RealTime Physics: active learning labs transforming the introductory laboratory, Eur. J. Phys. 28 S83-S94 (2007). 